\title{
Coengagement of $\alpha_{4} \beta_{1}$ integrin (VLA-4) and CD4 or CD8 is necessary to induce maximal Erk1/2 phosphorylation and cytokine production in human $\mathrm{T}$ cells
}

\author{
Tae Kon Kim ${ }^{1,3}$, Matthew J. Billard ${ }^{2,4}$, Eric D. Wieder ${ }^{1}$, Bradley W. Mclntyre ${ }^{2,3}$, and Krishna \\ V. Komanduri ${ }^{1,3}$ \\ ${ }^{1}$ Adult Stem Cell Transplant Program, University of Miami Sylvester Comprehensive Cancer Center, \\ Miami FL 33136 \\ ${ }^{2}$ Dept. of Immunology, The University of Texas M.D. Anderson Cancer Center, Houston TX 77030 \\ ${ }^{3}$ The Immunology Program of the University of Texas Health Science Center, Graduate School of \\ Biomedical Sciences \\ ${ }^{4}$ Dept. of Biostatistics and Bioinformatics, Center for Computational Immunology, Duke University, \\ Durham, NC 27705
}

\begin{abstract}
The $\alpha_{4} \beta_{1}$ integrin VLA-4 (very-late activation antigen-4) and the lineage-specific CD4 and CD8 receptors have been proposed as putative costimulatory receptors on $\mathrm{T}$ cells. To assess the relative contribution of signaling through the TCR, CD28 and these accessory molecules, we activated human $\mathrm{T}$ cells using soluble antibodies recognizing all four of these $\mathrm{T}$ cell receptor classes $(\mathrm{CD} 3, \mathrm{CD} 28$, CD4/CD8 and VLA-4) and assessed the degree of activation using higher-order flow cytometry detecting intracellular Erk1/2 phosphorylation and production of IL-2 and IFN $\gamma$. We found that: 1) costimulation via $\mathrm{CD} 4 / \mathrm{CD} 8$, in addition to $\mathrm{CD} 28$, is required for optimal $\mathrm{T}$ cell activation; 2) VLA-4 binding consistently potentiates CD4+ and CD8+ T cell activation; 3 ) augmentation of $\mathrm{T}$ cell activation through VLA-4 binding is most pronounced following engagement of CD4/CD8. These results confirm that multiple signals, including VLA-4 engagement, are necessary for maximal $\mathrm{T}$ cell activation beyond that induced via the TCR and CD28.
\end{abstract}

\section{Keywords}

co-stimulation; CD4; CD8; human; integrin; T lymphocyte

\section{Introduction}

Optimal stimulation of $\mathrm{T}$ cells in an immune response requires the binding of multiple ligands on antigen-presenting cells (APC) to costimulatory molecules on T cells[1]. Besides CD28,

\footnotetext{
(C) 2009 American Society for Histocompatibility and Immunogenetics. Published by Elsevier Inc. All rights reserved.

Correspondence should be addressed to: Krishna V. Komanduri, M.D., Adult Stem Cell Transplant Program, Division of Hematology/ Oncology, Dept. of Medicine, University of Miami Sylvester Comprehensive Cancer Center, 1121 NW 14th St. Rm. 311 (Mail Code: D8-4), Miami, FL 33136, Phone: 305.243.6355, Fax: 305.243.6361, kkomanduri@ med.miami.edu.

Publisher's Disclaimer: This is a PDF file of an unedited manuscript that has been accepted for publication. As a service to our customers we are providing this early version of the manuscript. The manuscript will undergo copyediting, typesetting, and review of the resulting proof before it is published in its final citable form. Please note that during the production process errors may be discovered which could affect the content, and all legal disclaimers that apply to the journal pertain.
} 
which is known to deliver the most important costimulatory signal to activate $\mathrm{T}$ cells[2], the $\mathrm{CD} 4$ or CD8 co-receptor has been shown to bind to the MHC class I or II molecule, respectively, in addition to the TCR and Ag:MHC complex. Monoclonal antibodies (mAbs) directed against CD4 and CD8 have been used in recent years to determine the functional significance of these molecules in T cell activation[3-6]. However, the extent to which CD4/CD8 engagement may directly influence TCR-dependent activation remains controversial.

Integrins are a large family of $\alpha \beta$ heterodimeric transmembrane proteins that mediate cell-cell and cell-extracellular matrix adhesion. Although a dual role of integrins as adhesion and costimulatory molecules has been proposed[7-13], less is known about how integrins may interact with other putative costimulatory molecules (e.g., CD4 or CD8) and whether integrin co-engagement is needed to induce optimal $\mathrm{T}$ cell activation.

We sought to characterize the relative importance of co-engagement of $\alpha_{4} \beta_{1}$ integrin VLA-4 (very late activation antigen-4, also identified as CD49d/CD29) and CD4/CD8 in potentiating activation induced by the TCR and CD28. To better mimic fluid interactions between putative costimulatory receptors in vitro, we developed an experimental system wherein human $\mathrm{T}$ cells are activated using soluble antibodies directed against CD3E[14], CD4 or CD8, CD28 and VLA-4, followed by secondary cross-linking. We then examined activation at a single-cell level using cytokine flow cytometry and intracellular assessment of the MAPK/Erk signaling pathway. In extension of the classical two-signal model (TCR/CD28) of T cell activation, we found that engagement of multiple cell surface receptors, including VLA-4, is required for maximal $\mathrm{T}$ cell activation.

\section{Material and Methods \\ Cells}

Peripheral blood T cells were purified from the buffy coats (Gulf Coast Regional Blood Center) of healthy donors as previously described[15]. The resultant lymphocyte population was routinely $>95 \%$ viable and $>85 \% \mathrm{CD} 3+$ as determined by flow cytometry.

\section{Cross-linking and $\mathrm{T}$ cell activation}

$10^{6}$ purified T cells were incubated with $0.1 \mu \mathrm{g} / \mathrm{ml}$ anti-CD3 $\mathrm{mAb}$ (clone: OKT3, Ortho Biotech, Bridgewater, NJ), and/or 5 $\mu \mathrm{g} / \mathrm{ml}$ anti-CD28 mAb (clone: L293, BD Biosciences), and/or $0.5 \mu \mathrm{g} / \mathrm{ml}$ anti-CD4 mAb (clone: OKT4), and/or $0.5 \mu \mathrm{g} / \mathrm{ml}$ anti-CD8 $\mathrm{mAb}$ (clone: OKT8, eBiosciences), and/or $1 \mu \mathrm{g} / \mathrm{ml}$ anti- $\alpha 4 \beta 1 \mathrm{mAb}$ (clone: $19 \mathrm{H} 8$ ) in 96 -well v-bottom plates in $200 \mu 1$ of PBS supplemented with 2\% FBS (Invitrogen, Carlsbad, CA) for $30 \mathrm{~min}$ on ice. Following washing, cells were incubated with $10 \mu \mathrm{g} / \mathrm{ml}$ anti-mouse IgG (Fc specific) $\mathrm{F}(\mathrm{ab}$ ') 2 fragment (Sigma) in 96-well v-bottom plates in 200 $\mu$ l of PBS supplemented with 2\% FBS for 30 min on ice. Following washing, cells were resuspended in warmed media supplemented with $10 \% \mathrm{FBS}$ and transferred to $37^{\circ} \mathrm{C}, 5 \% \mathrm{CO} 2$ incubator. After $5 \mathrm{~min}$, cells were fixed and permeabilized to assess the Erk1/2 phosphorylation. After $1 \mathrm{hr}$, brefeldin A (Sigma, St. Louis, MO) was added to enable accumulation of intracellular cytokines. Following an additional 5 $\mathrm{hr}$ incubation, we fixed and permeabilized cells with Fix \& Perm A/B (Caltag, Burlingame, CA) and assessed the simultaneous expression of surface markers and intracellular effector proteins.

\section{Assessment of Erk1/2 phosphorylation, VLA-4 expression, and cytokine production by flow cytometry}

Cells were stained with $\mathrm{mAb}$ specific for phospho-Erk1/2 (Cell Signal Technologies) followed by secondary Ab conjugated with Alexa Fluoro 647 (Molecular Probe, Invitrogen) and mAb conjugated with the fluorochromes FITC, PerCP-Cy5.5, APC, PE-Texas Red, APC-Alexa 
Fluor 750 or pacific blue and specific for human CD4, CD8, IL-2 (BD Pharmingen, San Jose, CA), CD45RA (Beckman Coulter, Fullerton, CA), CD27, IFN $\gamma$ (eBiosciences, San Diego, CA). $1 \mu \mathrm{g} / \mathrm{ml}$ anti- $\alpha 4 \beta 1 \mathrm{mAb}$ (clone: $19 \mathrm{H} 8$ ) for VLA-4 staining, and mouse IgG2a for isotype control followed by secondarily staining with APC conjugated anti-mouse IgG2a (Jackson ImmunoResearch laboratories, West Grove, PA). After staining, cells were washed, resuspended in PBS with 1\% paraformaldehyde, and analyzed by 6-color 8-parameter flow cytometry in a Cyan cytometer (Dako, Carpinteria, CA) or an LSRII cytometer (BD, San Jose, CA) using FlowJo software (Treestar, San Carlos, CA). For most analyses, at least $3 \times 10^{5}$ total events were analyzed, with sequential gating of PBMCs in a lymphocyte region (by scatter), on $\mathrm{T}$ cells (by assessing $\mathrm{CD} 4+$ or $\mathrm{CD} 8+$ ) and $\mathrm{CD} 45 \mathrm{RA}+\mathrm{CD} 27+$ to demarcate naïve and memory cells staining for $\alpha_{4} \beta_{1}$ integrin VLA4 and intracellular pERK1/2 and IL-2/IFN $\gamma$ ). Gates defining cytokine-positive populations were defined based on the upper limits of fluorescence of unstimulated cells stained with the same antibodies.

\section{Results and Discussion}

\section{Development of an in vitro activation system utilizing soluble mAbs and assessment of MAPK signaling and cytokine production at a single cell level by flow cytometry}

To date, the majority of studies examining costimulation in vitro have utilized immobilized $\mathrm{mAbs}$ or ligands to characterize the roles of individual activation signals. One caveat of these studies is that microdomain formation is inherently less flexible in these models, potentially leading to misinterpretation of the role of individual costimulatory molecules. A prior study by Geppert and Lipsky suggested that soluble anti-CD4 mAb could inhibit $\mathrm{T}$ cell activation induced by anti-CD3 $\mathrm{mAb}$ in contrast to immobilized anti-CD4 mAbs, which enhanced responses. Because the use of models utilizing soluble mAbs more closely recapitulates the in vivo $\mathrm{T}$ cell surface, microdomain formation in these models better reflects physiologic immunologic synapse formation, including the native roles of costimulatory molecules and their interactions[16]. Therefore, we evaluated the integration of signals delivered via the TCR, CD28, CD4/CD8 and VLA-4 following activation using soluble antibodies, followed by secondary cross-linking. To best discriminate heterogeneity of activation, we utilized singlecell assays including cytokine flow cytometry (CFC)[17-20] and phosphoflow assessment [21] to assess activation within subpopulations of CD4+ and CD8+ T cells. By using these assays, we were able to reduce and/or eliminate artifacts that may be associated with ex vivo culture by utilizing relatively brief stimulation periods ( $5 \mathrm{~min}$ for Erk $1 / 2$ phosphorylation and $6 \mathrm{hr}$ for CFC assays) and preventing events associated with longer stimulation, including proliferation and/or activation-induced cell death of subpopulations of responders.

\section{Costimulation via CD4/CD8, in addition to CD28, is required for optimal T cell activation}

It has been shown that soluble anti-CD3 mAb induces accessory cell dependent $\mathrm{T}$ cell proliferation through $\mathrm{Fc}$ receptors[14,22]. It has also been demonstrated that various interactions of surface proteins including LFA-1 and MHC molecules occur within APC:T cell synapses formed following anti-CD3 stimulation[23]. We first compared CD3 mAb-induced $\mathrm{T}$ cell activation in the presence and absence of APC (in PBMC and purified T cells, respectively). Erk1/2 phosphorylation in T cells was significantly increased in PBMC (data not shown), consistent with the hypothesis that the binding of anti- $\mathrm{CD} 3 \mathrm{mAb} F \mathrm{c}$ regions to $\mathrm{Fc}$ receptors of APC (including monocytes and B cells) induces further interaction between costimulatory molecules and ligands. In order to minimize the influence of unknown APCmediated interactions with $\mathrm{T}$ cell surface receptors, we utilized human $\mathrm{T}$ cells purified by negative selection.

We and others have demonstrated that assessments of functional human $\mathrm{T}$ cell responses using cytokine flow cytometry (CFC) correlate strongly with protective immunity in clinical settings. 
We have used these approaches to demonstrate clinically significant immune reconstitution in HIV-infected subjects $[18,19]$ and to identify individuals at risk for viral reactivation after allogeneic stem cell transplantation[20]. To better characterize the role of individual and multiple signals via the TCR, CD28, VLA-4, CD4 and CD8 in T cell activation in vitro, we induced the cross-linking of various combinations of mAbs directed at these surface proteins in purified T cells, and assessed phospho-Erk $1 / 2$ and measured intracellular cytokine production using assays previously validated in clinical studies. Because individual human subjects vary in the magnitude of stimulated $\mathrm{T}$ cell responses in vitro, we examined differences in the magnitude of activation induced by combinations of stimuli across a uniform group of healthy $\mathrm{T}$ cell donors. Of note, while baseline responses varied significantly, very similar patterns were observed in the pattern and magnitude of stimulation induced by combinations of agonists.

As expected, a suboptimal dose $(0.1 \mu \mathrm{g} / \mathrm{ml})$ of anti-CD3 $\mathrm{mAb}$ alone failed to induce substantial activation in either CD4+ or CD8+ T cells. The addition of CD28 mAb induced a modest increase of Erk1/2 phosphorylation (in CD4+ T cells), the production of IL-2 (in CD4+ and CD8+ T cells) and IFN $\gamma$ (CD8+), relative to anti-CD3 mAb (OKT3) alone (Lane 1/3 in Fig. 1 \& Fig. 2, $\mathrm{P}<0.05)$. In the presence of antibodies to $\mathrm{CD} 4$ or CD8, costimulation via CD28 consistently induced increased levels of activation in both CD4+ and CD8+ T cells (Lane 5/7 in Fig. 1 \& Fig. 2, $\mathrm{P}<0.05$ ). More interestingly, signals from CD4 or CD8 led to an increased amount of Erk1/2 phosphorylation, relative to that induced by antibody to CD28 alone, and the production of IL-2 and IFN $\gamma$ in the absence (Lane 1/5 in Fig. 1 \& Fig. 2, $\mathrm{P}<0.05$ ) or presence of CD28 mAbs (Lane 3/7 in Fig. 1 \& Fig. 2, P<0.05).

\section{Engagement of VLA-4 may augment, but not replace, CD28-mediated activation}

Consistent with the classical two-signal model of activation, the addition of a CD28-mediated signal to CD3 stimulation resulted in a significant increase in Erk1/2 phosphorylation in both CD4+ and CD8+ T cells (Lanes 1/3 in Fig. 1, P $<0.05$ ). Production of IL-2 and IFN $\gamma$ were also significantly increased, though the absolute increase was much less than seen for Erk1/2 activation (Lanes $1 / 3$ in Fig. 2, $\mathrm{P}<0.05$ ). In contrast, in the absence of CD28 signals, $\mathrm{mAb}$ stimulation via VLA-4 did not significantly increase either IL-2 or IFN $\gamma$ production, either in the absence (e.g., Lanes 1/2 in Fig. 2) or presence of activation via CD4 or CD8 (e.g., Lanes $5 / 6$ in Fig. 2). When assessing Erk1/2 phosphorylation, we similarly saw no increase in the absence of CD4/CD8 signals (Lanes 1/2 in Fig. 1), but did see an VLA-4-induced increase in Erk $1 / 2$ phosphorylation in the presence of CD3 and CD4/CD8 signals. These data suggest that binding via VLA-4 may only occasionally substitute for activation via CD28, and only then in the presence of signals delivered via CD4 or CD8.

In CD4+ T cells already stimulated in the presence of mAbs directed against CD3/CD4/CD28, additional stimulation via $\alpha_{4} \beta_{1}$ integrin significantly increased the level of Erk1/2

phosphorylation (lanes 7/8 in Fig. 1) and both IL-2/IFN $\gamma$ production (lanes 7/8 in Fig. 2). In CD8+ T cells, Erk1/2 phosphorylation was similarly augmented (lanes $7 / 8$ in Fig. 1) but there was no significant difference in IL-2 or IFN $\gamma$ production observed (lanes $7 / 8$ in Fig. 2). We confirmed the specificity of these results demonstrating the importance of VLA-4 ligation using three separate mAbs recognizing unique motifs in the $\alpha 4 \beta 1$ heterodimer (90B8: $\alpha 4,33 \mathrm{~B} 6: \beta 1$, 19H8: $\alpha 4 \beta 1$ ); qualitative results were similar using all three antibodies, although the extent of activation measured by Erk $1 / 2$ phosphorylation and cytokine production was greater in $T$ cells activated using 19H8, which recognizes both $\alpha$ and $\beta$ subunits (data not shown).

In order to determine whether the augmentation of $\mathrm{T}$ cell activation by VLA-4 ligation differs in T cell maturation subsets, we evaluated the expression of VLA-4, the phosphorylation of Erk1/2 and the production of IL-2 in maturation CD4+ T cell lineages, demarcated by CD45RA and CD27 staining (Naïve (N): CD45RA+CD27+, Early memory (M1): CD45RA-CD27+, 
Intermediate memory (M2): CD45RA-CD27-, Late memory (M3): CD45RA+CD27-). M3 CD4+ cells are only rarely found in healthy individuals, so CD4+ analyses were confined to M1 and M2 memory T cell subsets. Although naïve CD4+ T cells expressed VLA-4, its costimulatory effect on phosphorylation of Erk1/2 and IL-2 production was not significant (Fig. 3). In contrast, M1 and M2 memory cells expressed higher levels of VLA-4 and demonstrated significantly augmented phophorylation of Erk1/2 and IL-2 production in both CD4 and CD8 lineages (Fig. 3). Very similar results were observed in the CD8+ T cell compartment (data not shown).

\section{Conclusions and therapeutic implications}

Prior studies have suggested that VLA-4 may function as a costimulatory receptor in human $\mathrm{T}$ cells. However, these studies have utilized stimulation using immobilized ligands (e.g., on plastic) [16] and did not address precisely how signals through VLA-4 may integrate with those delivered via other surface receptors involved in $\mathrm{T}$ cell activation. To overcome limitations of prior studies, we examined relatively rapid functional endpoints, including assessment of Erk $1 / 2$ phosphorylation within minutes of stimulation and cytokine flow cytometry within hours, and utilized a system wherein soluble antibodies were directed against $\mathrm{T}$ cell surface proteins and then secondarily cross-linked. This also allowed us to use relatively unmanipulated primary human T cells (i.e., as opposed to less physiologic Jurkat cells or transformed $\mathrm{T}$ cell blasts) to model the activation of native human $\mathrm{T}$ cells freshly isolated from healthy subjects.

We recently have shown that naïve and memory T cells functionally differ in IL-2/IFN $\gamma / \mathrm{MIP1}$ $\beta$ production (Kim et al., in press). To determine whether the VLA-4 effect may vary based on memory differentiation, we analyzed the expression of VLA-4 in T cell maturation subsets defined by CD45RA and CD27. Consistent with prior evidence [15], we confirmed that naïve $\mathrm{T}$ cells express VLA-4 at a lower level than memory T cells. Using 6-color flow cytometry, we confirmed that the augmentation of Erk1/2 phosphorylation and IL- 2 production by VLA-4 is significant in memory $\mathrm{T}$ cells, and not in naïve $\mathrm{T}$ cells, consistent with the requirement of high-level VLA-4 expression for costimulatory function.

Using single cell analyses, we consistently demonstrated that co-engagement of VLA-4 and CD4/8 on the T cell surface, in addition to the TCR and CD28, induces a higher degree of Erk1/2 phosphorylation and more robust production of IL-2 and IFN $\gamma$. In this system, we found that: 1) VLA-4 binding consistently potentiates CD4+ and CD8+ T cell activation, as evidenced by augmented Erk1/2 phosphorylation and the production of both IL-2 and IFN $\gamma$; 2) VLA-4 binding appears to have a more pronounced effect in the presence of signals triggered via CD4 and $\mathrm{CD} 8$, with little augmentation of $\mathrm{CD} 3 / \mathrm{CD} 28$ stimulation in the absence of Abs directed at $\mathrm{CD} 4$ or $\mathrm{CD} 8$; 3) costimulation via CD4/CD8, in addition to CD28, significantly potentiates $\mathrm{T}$ cell activation; 4) VLA-4 binding augmented Erk1/2 phosphorylation and the IL-2 production in memory, but not in naïve subsets; 5 ) coengagement of multiple costimulatory receptors, including VLA-4, is required for optimal T cell activation.

Further studies will be required to define the mechanism by which coengagement of VLA-4 and $\mathrm{CD} 4 / \mathrm{CD} 8$ potentiate $\mathrm{CD} 3 / \mathrm{CD} 28$-mediated $\mathrm{T}$ cell activation. The mechanisms for the significant effects of coengagement of CD4/CD8 on T cell activation also deserve further exploration. Berzofsky and colleagues have demonstrated that high avidity CD8+ T cells have increased surface expression of CD8 $\alpha \beta$ [24]. Our results also confirm that antibodies directed at either $\alpha_{4}$ or $\beta_{1}$ subunits, or at the $\alpha_{4} \beta_{1}$ heterodimer, augment T cell activation and demonstrate clearly that integrins may directly act as costimulatory receptors beyond their independent role in mediating leukocyte adhesion. Finally, our results suggest that the use of selective $\mathrm{mAb}$ agonists targeting VLA-4 should have value in stimulating T cell responses in vivo (e.g., in the 
setting of therapeutic immunization[25,26]) or during ex vivo expansion of T cells for adoptive immunotherapy.

\section{Acknowledgments}

This project was supported by grants to K.V.K. from the NIH (NCI RO1 CA109326 and NHLBI RO1 HL091749) and the Leukemia and Lymphoma Society Translational Research Program. The authors thank Qing Ma (MDACC) and Cara Benjamin ( $\mathrm{U}$ of Miami) for insightful advice and critical review of the manuscript, Lisa St. John (MDACC) for excellent technical assistance and David He and Karen Ramirez (MDACC) for assistance optimizing the flow cytometric approach.

\section{References}

1. Dustin ML, Shaw AS. Costimulation: building an immunological synapse. Science 1999;283(5402): 649. [PubMed: 9988658]

2. Ledbetter JA, Imboden JB, Schieven GL, Grosmaire LS, Rabinovitch PS, Lindsten T, Thompson CB, June CH. CD28 ligation in T-cell activation: evidence for two signal transduction pathways. Blood 1990;75(7):1531. [PubMed: 2156582]

3. Emmrich F, Strittmatter U, Eichmann K. Synergism in the activation of human CD8 T cells by crosslinking the T-cell receptor complex with the CD8 differentiation antigen. Proc Natl Acad Sci U S A 1986;83(21):8298. [PubMed: 3095833]

4. Haughn L, Gratton S, Caron L, Sekaly RP, Veillette A, Julius M: Association of tyrosine kinase p56lck with CD4 inhibits the induction of growth through the alpha beta T-cell receptor. Nature 1992;358 (6384):328. [PubMed: 1322497]

5. Veillette A, Bolen JB, Bookman MA: Alterations in tyrosine protein phosphorylation induced by antibody-mediated cross-linking of the CD4 receptor of T lymphocytes. Mol Cell Biol 1989;9(10): 4441. [PubMed: 2479826]

6. Takahashi K, Nakata M, Tanaka T, Adachi H, Nakauchi H, Yagita H, Okumura K. CD4 and CD8 regulate interleukin 2 responses of T cells. Proc Natl Acad Sci U S A 1992;89(12):5557. [PubMed: 1608966]

7. Bachmann MF, McKall-Faienza K, Schmits R, Bouchard D, Beach J, Speiser DE, Mak TW, Ohashi PS. Distinct roles for LFA-1 and CD28 during activation of naive T cells: adhesion versus costimulation. Immunity 1997;7(4):549. [PubMed: 9354475]

8. Bednarczyk JL, Teague TK, Wygant JN, Davis LS, Lipsky PE, McIntyre BW. Regulation of T cell proliferation by anti-CD49d and anti-CD29 monoclonal antibodies. J Leukoc Biol 1992;52(4):456. [PubMed: 1383369]

9. Van Seventer GA, Shimizu Y, Horgan KJ, Shaw S. The LFA-1 ligand ICAM-1 provides an important costimulatory signal for T cell receptor-mediated activation of resting T cells. J Immunol 1990;144 (12):4579. [PubMed: 1972160]

10. Van Seventer GA, Bonvini E, Yamada H, Conti A, Stringfellow S, June CH, Shaw S. Costimulation of $\mathrm{T}$ cell receptor/CD3-mediated activation of resting human CD4+ T cells by leukocyte functionassociated antigen-1 ligand intercellular cell adhesion molecule-1 involves prolonged inositol phospholipid hydrolysis and sustained increase of intracellular Ca2+ levels. J Immunol 1992;149 (12):3872. [PubMed: 1360995]

11. Udagawa T, Woodside DG, McIntyre BW. Alpha 4 beta 1 (CD49d/CD29) integrin costimulation of human $\mathrm{T}$ cells enhances transcription factor and cytokine induction in the absence of altered sensitivity to anti-CD3 stimulation. J Immunol 1996;157(5):1965. [PubMed: 8757316]

12. Udagawa T, McIntyre BW. A VLA-4 alpha-chain specific monoclonal antibody enhances CD3induced IL-2/IL-2 receptor-dependent T-cell proliferation. Lymphokine Cytokine Res 1992;11(5): 193. [PubMed: 1467362]

13. Mainiero F, Gismondi A, Soriani A, Cippitelli M, Palmieri G, Jacobelli J, Piccoli M, Frati L, Santoni A. Integrin-mediated ras-extracellular regulated kinase (ERK) signaling regulates interferon gamma production in human natural killer cells. J Exp Med 1998;188(7):1267. [PubMed: 9763606]

14. Van Wauwe JP, De Mey JR, Goossens JG. OKT3: a monoclonal anti-human T lymphocyte antibody with potent mitogenic properties. J Immunol 1980;124(6):2708. [PubMed: 6966296] 
15. Billard MJ, McIntyre BW. CD45RA T-cell activation without proliferation by a partial agonist monoclonal antibody to beta1 integrin. Immunol Cell Biol 2008;86(4):381. [PubMed: 18195724]

16. Geppert TD, Lipsky PE. Activation of T lymphocytes by immobilized monoclonal antibodies to CD3. Regulatory influences of monoclonal antibodies to additional T cell surface determinants. J Clin Invest 1988;81(5):1497. [PubMed: 2452835]

17. Waldrop SL, Pitcher CJ, Peterson DM, Maino VC, Picker LJ. Determination of antigen-specific memory/effector CD4+ T cell frequencies by flow cytometry: evidence for a novel, antigen-specific homeostatic mechanism in HIV-associated immunodeficiency. J Clin Invest 1997;99(7):1739. [PubMed: 9120019]

18. Komanduri KV, Viswanathan MN, Wieder ED, Schmidt DK, Bredt BM, Jacobson MA, McCune JM. Restoration of cytomegalovirus-specific CD4+ T-lymphocyte responses after ganciclovir and highly active antiretroviral therapy in individuals infected with HIV-1. Nat Med 1998;4(8):953. [PubMed: 9701250]

19. Komanduri KV, Feinberg J, Hutchins RK, Frame RD, Schmidt DK, Viswanathan MN, Lalezari JP, McCune JM. Loss of cytomegalovirus-specific CD4+ T cell responses in human immunodeficiency virus type 1-infected patients with high CD4+ T cell counts and recurrent retinitis. J Infect Dis 2001;183(8):1285. [PubMed: 11262214]

20. Ozdemir E, St John LS, Gillespie G, Rowland-Jones S, Champlin RE, Molldrem JJ, Komanduri KV. Cytomegalovirus reactivation following allogeneic stem cell transplantation is associated with the presence of dysfunctional antigen-specific CD8+ T cells. Blood 2002;100(10):3690. [PubMed: 12393402]

21. Perez OD, Nolan GP. Simultaneous measurement of multiple active kinase states using polychromatic flow cytometry. Nat Biotechnol 2002;20(2):155. [PubMed: 11821861]

22. Chang TW, Kung PC, Gingras SP, Goldstein G. Does OKT3 monoclonal antibody react with an antigen-recognition structure on human T cells? Proc Natl Acad Sci U S A 1981;78(3):1805. [PubMed: 6165018]

23. Geppert TD, Lipsky PE. Accessory cell-T cell interactions involved in anti-CD3-induced T4 and T8 cell proliferation: analysis with monoclonal antibodies. J Immunol 1986;137(10):3065. [PubMed: 3095421]

24. Oh S, Perera LP, Burke DS, Waldmann TA, Berzofsky JA. IL-15/IL-15Ralpha-mediated avidity maturation of memory CD8+ T cells. Proc Natl Acad Sci U S A 2004;101(42):15154. [PubMed: 15477598]

25. Hodge JW, Rad AN, Grosenbach DW, Sabzevari H, Yafal AG, Gritz L, Schlom J. Enhanced activation of $\mathrm{T}$ cells by dendritic cells engineered to hyperexpress a triad of costimulatory molecules. J Natl Cancer Inst 2000;92(15):1228. [PubMed: 10922408]

26. Yang S, Hodge JW, Grosenbach DW, Schlom J. Vaccines with enhanced costimulation maintain high avidity memory CTL. J Immunol 2005;175(6):3715. [PubMed: 16148117] 
a
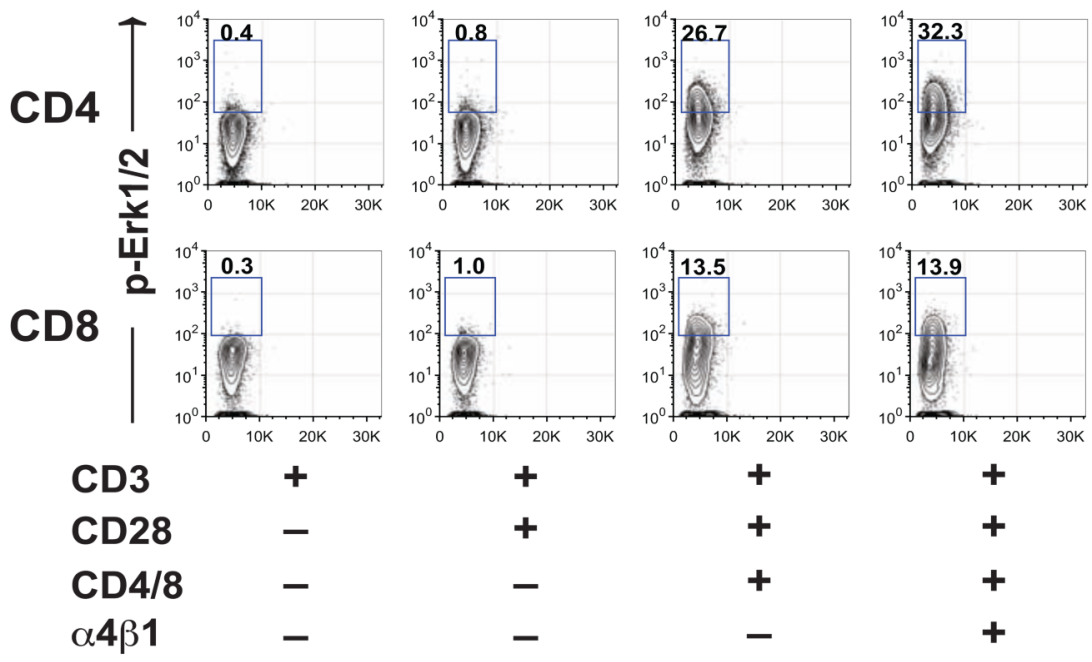

b

\section{CD4}

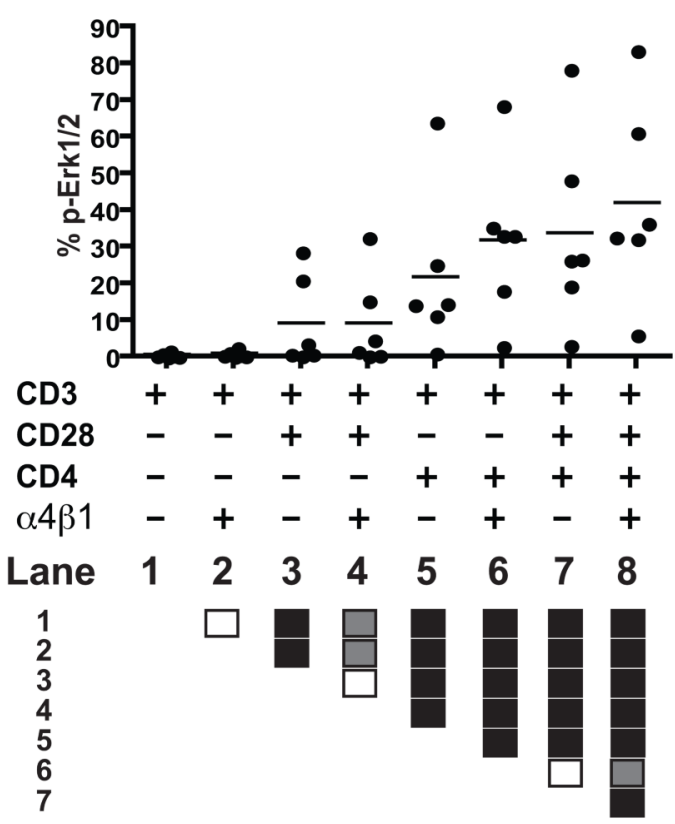

CD8

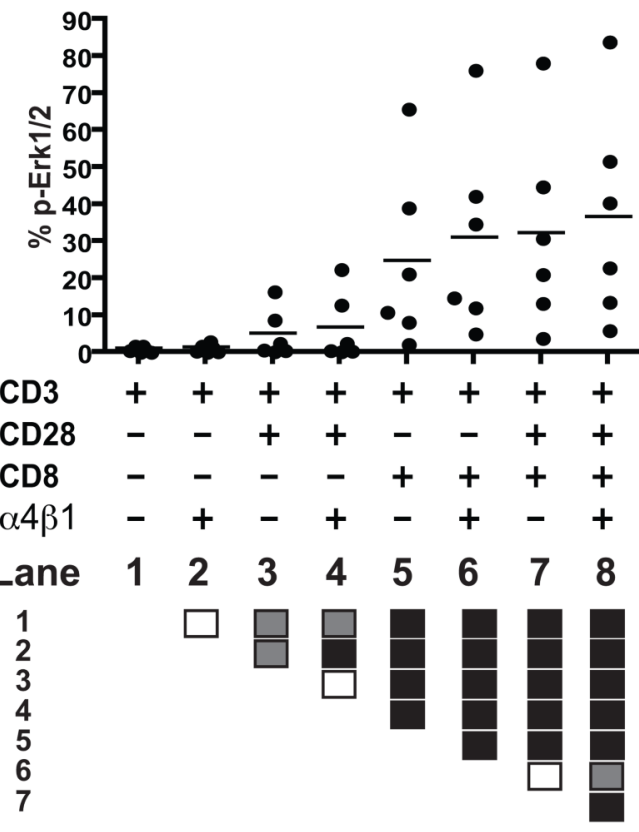

$\square<0.05 \square \mathrm{P}<0.1 \square \mathrm{NS}$

Figure 1. Co-engagement of $\alpha_{4} \beta_{1}$ integrin and CD4/CD8 results in maximal Erk1/2 phosphorylation

(a) Representative Erk1/2 phosphorylation in CD4+ and CD8+ T cells from a single subject, demonstrating augmented activation following CD3/D28 stimulation following co-

engagement of VLA-4 and CD4 or CD8. (b) Scatter plots demonstrating the synergistic effect of $\alpha_{4} \beta_{1}$ integrin and CD4/CD8 co-engagement on intracellular Erk1/2 phosphorylation in CD4 + and CD8+ T cells from six healthy donors. Intergroup comparisons were performed using the Wilcoxon signed-rank test. All $\mathrm{P}$ values were two-tailed and considered significant if less than 0.05 (filled black box, lower panel). Positive trends $(\mathrm{P}<0.1)$ are also indicated (filled gray box, lower panel). 
a

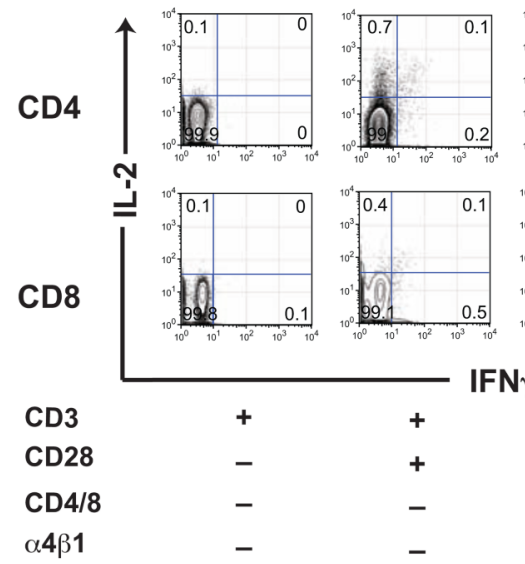

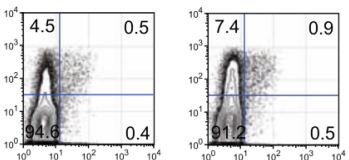

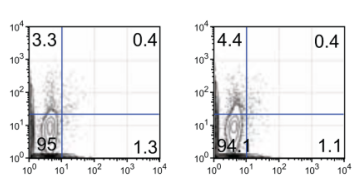

$\mathbf{N} \gamma$

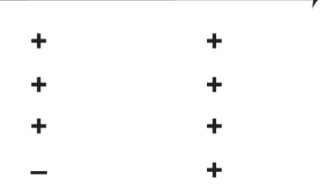

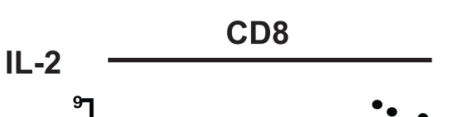
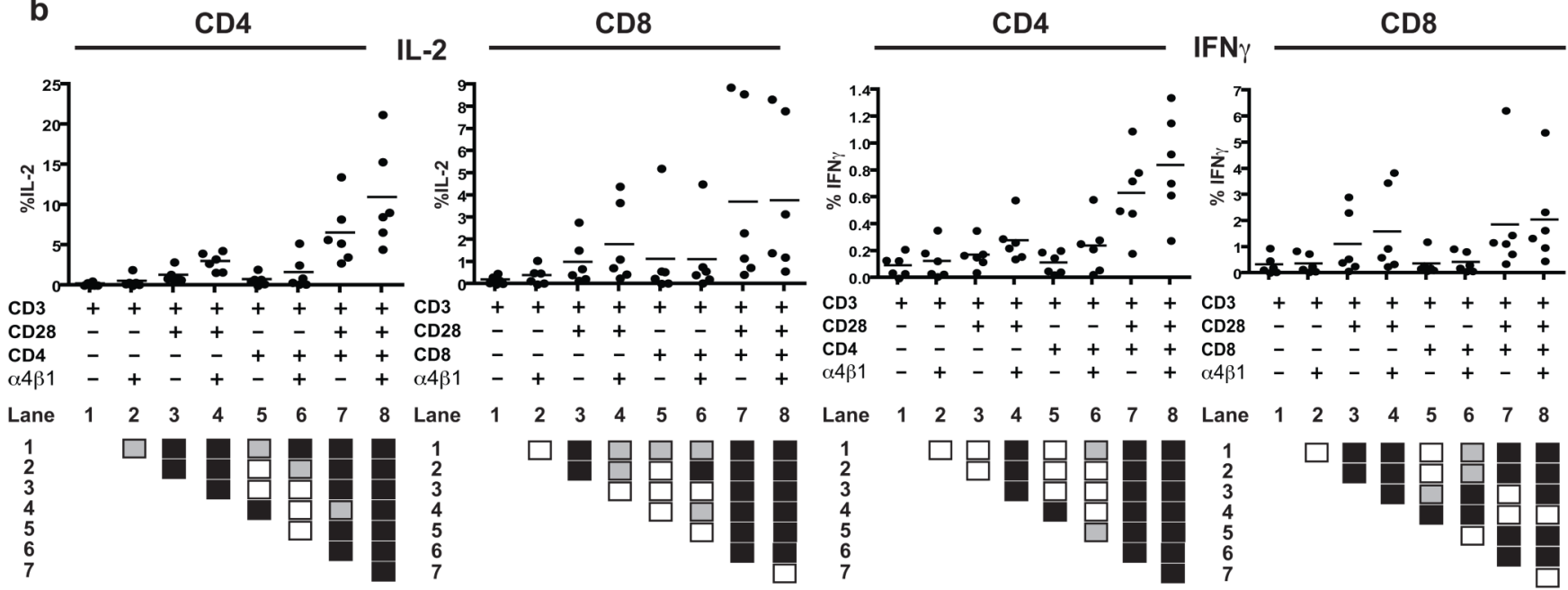

$\mathrm{P}<0.05 \square \mathrm{P}<0.1 \square \mathrm{NS}$

Figure 2. Co-engagement of $\alpha_{4} \beta_{1}$ integrin and CD4/CD8 results in maximal CD4+ and CD8+ T cell cytokine production

(a) Representative IL-2/IFN $\gamma$ production in CD4+ and CD8+ T cells from a single subject, demonstrating augmented activation following CD3/CD28 stimulation following co-

engagement of VLA-4 and CD4 or CD8. (b) Scatter plots demonstrating the synergistic effect of $\alpha_{4} \beta_{1}$ integrin and CD4/CD8 co-engagement on IL- 2 and IFN $\gamma$ production in CD4+ and CD8 $+\mathrm{T}$ cells from six healthy donors. Intergroup comparisons were performed using the Wilcoxon signed-rank test. All P values were two-tailed and considered significant if less than 0.05 (filled black box, lower panel). Positive trends $(\mathrm{P}<0.1)$ are also indicated (filled gray box, lower panel). 
b
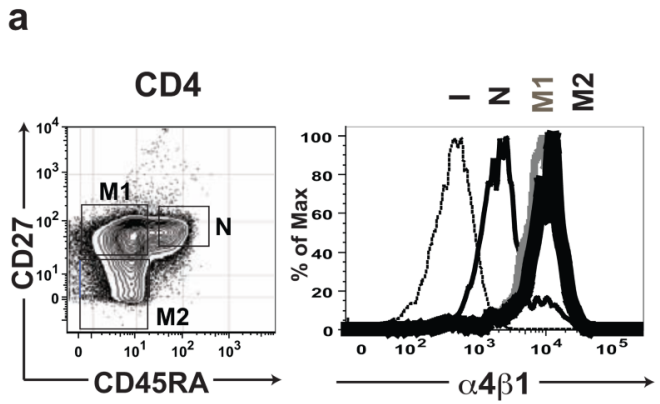

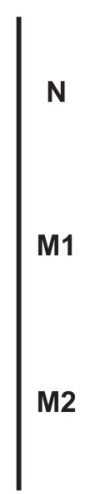

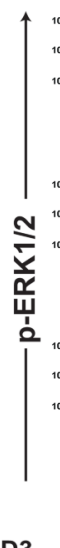
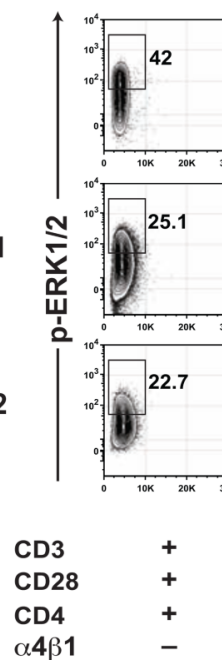

$+$

$+$

$-$

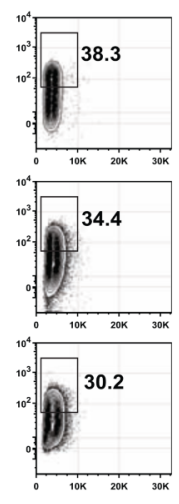

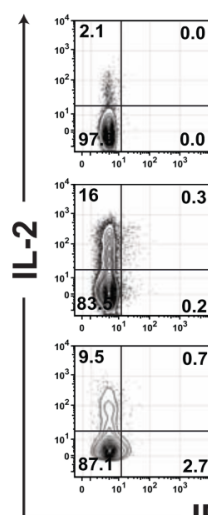
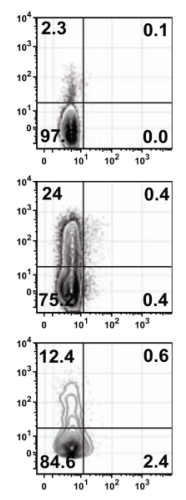

IFN $\gamma$

C
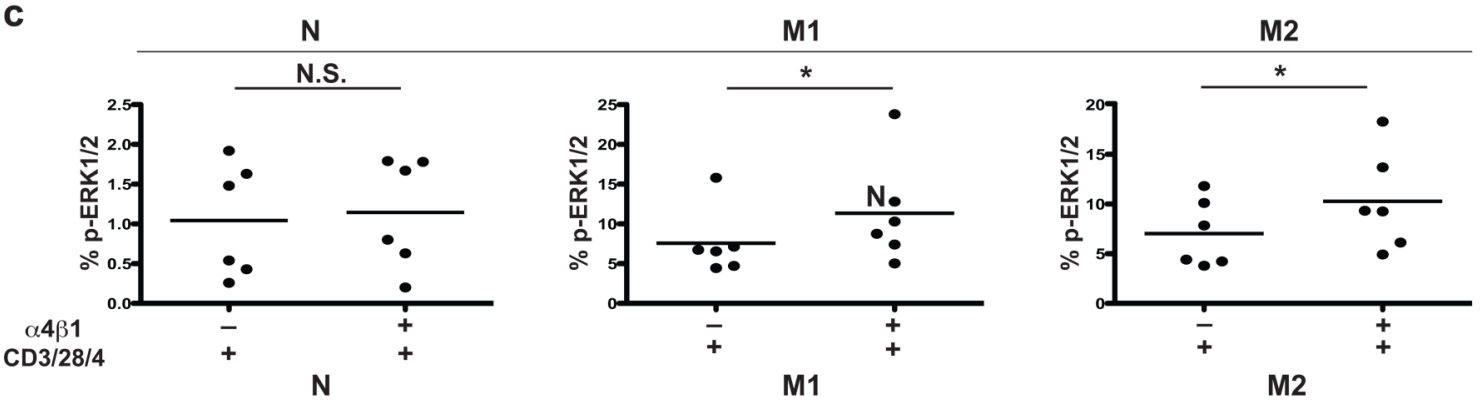

CD3/28/4
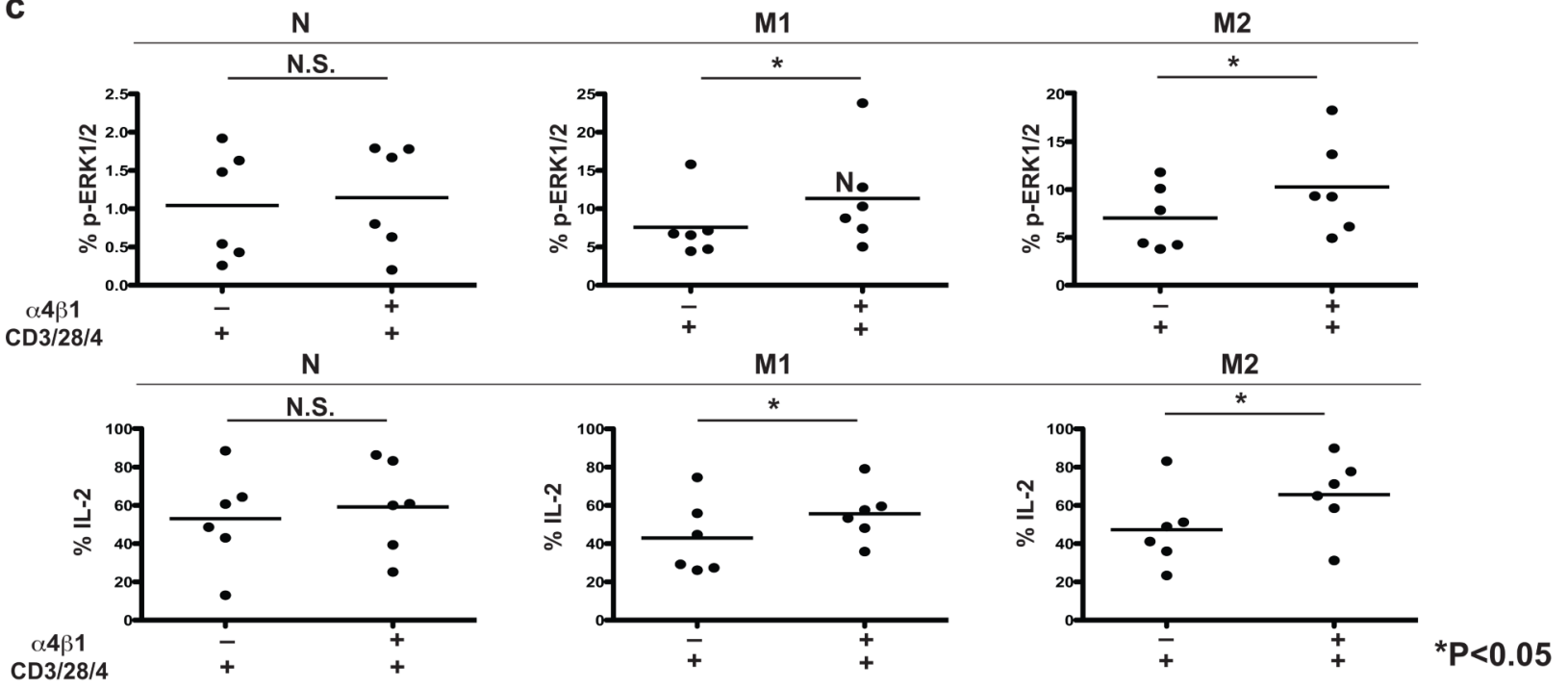

Figure 3. Co-engagement of $\alpha_{4} \beta_{1}$ integrin augments Erk1/2 phosphorylation and the production of IL-2 in memory $T$ cells

(a) Representative CD45RA/CD27 and $\alpha_{4} \beta_{1}$ integrin VLA-4 staining in CD4 T cells. CD45RA/ CD27 delineates CD4 T cell maturation subsets (naïve (N): CD45RA+CD27+, early memory (M1): CD45RA-CD27+, intermediate memory (M2): CD45RA-CD27-) (left). The expression of $\alpha_{4} \beta_{1}$ integrin in memory CD4 T cell subsets (M1, M2) is higher than naïve subset (I: isotype control (black dot), N: naïve (thin black), M1: early memory (thick gray), M2: intermediate memory (thick black)) (right). (b) Representative Erk1/2 phosphorylation (left) and IL-2/IFN $\gamma$ production (right) in CD4+ T cell maturation subsets from a single subject, demonstrating augmented activation in memory CD4+ T cell subsets (M1, M2) following CD3/ CD28/CD4 stimulation following co-engagement of VLA-4. For the most analyses, at least 300,000 total events were acquired, with sequential gating of PBMC in a lymphocyte region by scatter, on CD4+ T cells and assessment of intracellular p-Erk1/2 and IL-2 \& IFN $\gamma$ within three naïve and memory $T$ cell maturation subsets demarcated by CD45RA and CD27 expression. 2-D dot plots reflect p-Erk1/2 on side scatter and IL-2 vs. IFN $\gamma$ staining. (c) Scatter plots demonstrating the synergistic effect of $\alpha_{4} \beta_{1}$ integrin on intracellular Erk $1 / 2$ phosphorylation and IL-2/IFN $\gamma$ production in CD4+ T cells from six healthy donors. Intergroup 
comparisons were performed using the Wilcoxon signed-rank test. N.S.: not significant, * $\mathrm{P}<0.05$. 